\title{
Specificities of olfactory receptor neuron responses to amino acids in the black bullhead catfish (Ameiurus melas)
}

\author{
Jurij Dolensek • Tine Valentincic
}

Received: 1 April 2009 /Revised: 16 August 2009 /Accepted: 25 August 2009/Published online: 13 September 2009

(C) The Author(s) 2009. This article is published with open access at Springerlink.com

\begin{abstract}
In vivo investigations of catfish olfactory receptor neurons (ORNs) were previously limited to studying responses of spontaneously active cells. The olfactory organ, however, also contains ORNs that lack spontaneous activity and respond to amino acids. To record electrical activity of ORNs that were inactive prior to stimulation, we bathed the olfactory organ with low conductive, highly purified water that reduces shunting and enables detection of action potentials from ORNs distant to the electrode. After stimulation with amino acids, these ORNs elicited either phasic-tonic or tonic only activities. The spike frequency of the phasic activity consisted of transient frequencies up to $108 \mathrm{~Hz}$ that lasted $<450 \mathrm{~ms}$. All tonic activities saturated at action potential frequencies of $17-$ $21 \mathrm{~Hz}$. Their durations were dose dependent over several $\log$ units of concentration as they closely followed that of the suprathreshold amino acid stimulation. Specificities of 44 ORNs were investigated with ten different amino acids tested at $10^{-4} \mathrm{M}$. Thirteen ORNs were excited by only one amino acid, L-norvaline, and 22 additional ORNs were excited by L-norvaline and L-methionine. Nine ORNs were excited by $>2$ amino acids that included L-norvaline. In 29 of 31 neurons responding to $>1$ amino acid, the duration of the responses to the most stimulatory amino acid was at least double compared to that to the other amino acids. The
\end{abstract}

\footnotetext{
T. Valentincic $(\square)$

Department of Biology, University of Ljubljana,

Vecna pot 111,

Ljubljana, Slovenia

e-mail: tine.valentincic@bf.uni-lj.si

J. Dolensek

Institute of Physiology, University of Maribor,

Slomskov trg 15,

Maribor, Slovenia

e-mail: jurij.dolensek@uni-mb.si
}

amplitude of electro-olfactogram (EOG) correlated significantly with the number of ORNs activated by the same amino acids confirming that the EOG represents the sum of ORN receptor potentials.

Keywords Olfaction · Receptor cells · Amino acids · Electrophysiology $\cdot$ Fish

\section{Introduction}

Teleost fishes that do not hunt primarily by vision use olfaction in food search and social interactions [62]. Amino acids are detected with high acuity by the sense of smell as olfactory thresholds for the more stimulatory amino acids are in the nano- to micromolar range [7, 28]. Previous electrophysiological investigations of single catfish olfactory receptor neurons (ORNs) to amino acids studied only spontaneously active neurons [34, 35, 47, 63]. In these studies, the spontaneous activity of ORNs served as a beacon for the proper placement of the extracellular recording electrode. ORN responses to amino acids consisted of either an increase (excitation) or decrease (suppression) in the number of action potentials recorded. In both channel $[34,35,47]$ and bullhead (Valentincic et al., unpublished data) catfishes, most spontaneously active ORNs stimulated with amino acids responded with suppression. In zebrafish, however, most of the spontaneously active ORNs investigated were excited by amino acids $[21,22]$. In catfish, before stimulation, the mitral cell activities are presumably maintained by ORNs spontaneous activities; the suppressive ORN responses during stimulation render the same mitral cells less active [34, 46, 52]. The discrepancy between numerous ORNs' suppressive responses to amino acid stimulation and excitatory 
responses of numerous mitral cells in the coding glomeruli has never been resolved. The suppressive responses of catfish ORNs were mostly nonspecific as the activities were suppressed by several different types of amino acids $[34,35,47]$. Low specificity of ORNs lacking spontaneous activity was reported in amphibians and rodents since most neurons in the reports were excited by many different odorants [14-16, 51]. ORNs of Xenopus laevis tadpoles monitored through calcium labeling technique also responded to many chemically dissimilar amino acid stimuli [41].

Few studies in vertebrates reported the responses of ORNs that lack or have very low frequency of spontaneous activity and which were excited by olfactory stimuli $[12-16,24,32,33,43]$. Our preliminary investigations in black bullhead catfish (Ameiurus melas) where artificial pond water bathed the olfactory organ suggested that some of the ORNs that were excited by amino acids lacked spontaneous activity [63]. Olfactory organs of freshwater fish function in natural waters that contain few ions and also in artificial pond water that contains $\sim 1,000 \times$ fewer ions than do Ringer's solutions or the mucus overlying the ORNs of land vertebrates. It was thus expected that the olfactory organs of freshwater fish should also function in highly purified water (HPW) that contains $\sim 1,000,000 \times$ fewer ions than the extracellular solutions. In HPW, there was little shunting of the electrical responses of ORNs, which enabled us to locate amino acid responding ORNs irrespective of their spontaneous activity.

Fully functional ORNs lacking spontaneous activity were routinely observed in HPW. Most of the ORNs that lacked spontaneous activity responded with the longest response to only one of the tested amino acids, thus indicating its specificity. All tested ORNs reached a saturated tonic response of $17-21 \mathrm{~Hz}$ during an approximately tenfold increase of the odorant concentration over its threshold. We showed that the longest olfactory responses indicating specificity occurred after stimulation with the amino acid that has the lowest olfactory threshold. Therefore, the amino acid specificity of single ORNs was determined by their response duration at a single amino acid concentration (in most cases $10^{-4} \mathrm{M}$ ) of the applied stimulus. We also present evidence that the relative magnitude of the electroolfactogram (EOG) to amino acid was predictable [49] based on the proportion of spontaneously inactive ORNs that were excited by the amino acid tested.

\section{Materials and methods}

\section{Animals}

Black bullhead catfish (A. melas; 50-196 g body weight) were captured in ponds near Maribor (Slovenia). Groups of
100 catfish were maintained in aerated 500-1 polyethylene tanks at temperature of $17-20^{\circ} \mathrm{C}$. Several weeks before the experiments, the catfish were transferred into 80-1 aquaria and maintained individually at $20-25^{\circ} \mathrm{C}$ and $16: 8 \mathrm{~h}$ daynight cycle. Before each experiment, each catfish was anesthetized in ethyl 3-aminobenzoate methanesulfonate solution (MS-222, Fluka) at 1:5,000 dilution and immobilized with an intramuscular injection of gallamine triethiodide (Flaxedil, $0.38 \mathrm{mg}$ per $100 \mathrm{~g}$ weight, Aldrich). The anesthetized and immobilized catfish was wrapped in wet tissue paper and, its head was fixed in place with plastic bars attached to a Plexiglas chamber. Aerated tap water (TW) containing the anesthetic was continuously flushed over the gills through the Y-tubing inserted under the opercula. To expose the olfactory organ, the skin and bones above the nasal cavity were surgically removed. The olfactory cavity was perfused with HPW (Milli-Q185). The electrical resistance of the HPW measured at the outlet of the apparatus was $>18.2 \mathrm{M} \Omega \mathrm{cm}$.

\section{Stimuli}

Ten amino acids of the highest purity ( $>99 \%)$ were purchased from Fluka Chemie AG, Switzerland: [L-alanine (L-Ala, A), L-leucine (L-Leu, L), L-isoleucine (L-Ile, L), and L-proline (L-Pro, P)] and Sigma-Aldrich Inc., USA [L-serine (L-Ser, S), L-methionine (L-Met, M), L-valine (L-Val, V), Lnorvaline (L-nVal, $\mathrm{n}$ ), and L-arginine hydrochloride (L$\mathrm{ArgHCl}, \mathrm{R})$ ]. L-Lysine hydrochloride originated from BDH Chemicals Ltd., England. The amino acids were dissolved in HPW in $10 \mathrm{ml}$ polystyrene disposable beakers $<1 \mathrm{~h}$ before each experiment. The injected concentration of amino acids was $10^{-4} \mathrm{M}$ except for $10^{-2} \mathrm{ML}-$ Pro. For testing mixtures, the concentration of each amino acid in the mixture was $10^{-4} \mathrm{M}$ except for the $10^{-2} \mathrm{ML}$-Pro. The $\mathrm{pH}$ of $10^{-4} \mathrm{M}$ amino acids tested was the same as the $\mathrm{pH}$ of the HPW alone ( $\mathrm{pH} 4.1-4.9)$. No damaging effects due to the HPW were observed during single unit recordings from either spontaneously inactive or spontaneously active ORNs.

Stimulation of the olfactory epithelium

The exposed olfactory epithelium was continuously irrigated at $18 \mathrm{ml} / \mathrm{min}$ with HPW. In HPW, the concentrations of $\mathrm{Na}^{+}(7 \pm 2 \mu \mathrm{g} / \mathrm{l}), \mathrm{K}^{+}(50 \pm 5 \mu \mathrm{g} / \mathrm{l}), \mathrm{Ca}^{++}(5 \pm 2 \mu \mathrm{g} / \mathrm{l})$, and $\mathrm{Mg}^{++}(0.5 \pm 0.1 \mu \mathrm{g} / \mathrm{l})$ were $\sim 1,000 \times$ lower than in the artificial pond water [11, 36, 42]. In control experiments, the ion concentrations in the water entering the olfactory cavity were $\mathrm{Na}^{+}(8 \pm 2 \mu \mathrm{g} / \mathrm{l}), \mathrm{K}^{+} 64 \pm 5 \mu \mathrm{g} / \mathrm{l}, \mathrm{Ca}^{++} 16 \pm 2 \mu \mathrm{g} / \mathrm{l}$, and $\mathrm{Mg}^{++} 2 \pm 0.1 \mu \mathrm{g} / \mathrm{l}$, whereas in the water exiting the olfactory cavity, the concentrations of these ions were $\mathrm{Na}^{+} 30 \pm 2 \mu \mathrm{g} /$ $1, \mathrm{~K}^{+} 45 \pm 5 \mu \mathrm{g} / 1, \mathrm{Ca}^{++} 12 \pm 2 \mu \mathrm{g} / 1$, and $\mathrm{Mg}^{++} 2 \pm 0.1 \mu \mathrm{g} / 1$. Gravity-fed HPW entered into a Y-tube containing irriga- 
tion and stimulus water; the tubes were re-connected by a T-bore stopcock that delivered water into the outlet tube (0.8 $\mathrm{mm}$ internal diameter), which was positioned with a micromanipulator at a distance of $2-4 \mathrm{~mm}$ from the olfactory rosette. Test solutions $(0.5 \mathrm{ml})$ were applied via a tuberculin syringe into the T-tube located in the middle of the stimulus tube. To inject the stimulus, the T-bore stopcock redirected water flow from the irrigation into the stimulus tube.

\section{Calibrating the stimulus duration}

Visual observation of the Congo red solution injected into the stimulus tube indicated that the stimulus reached the catfish olfactory cavity 1 to $3 \mathrm{~s}$ after its introduction into the stimulus tube. Kinocilia mix the stimulus solution and HPW within the olfactory cavity and drive fast microcurrents between olfactory lamellae. The concentration of the stimulus solution at the end of stimulus delivery in the nasal cavity, depending on the size of the fish, was $67-99 \%$ of its injected concentration. To determine the duration that the presented stimulus remained above threshold for an ORN, the rate of stimulus wash-out from the nasal cavity was calculated using a simple dilution assumption whereby the stimulus concentration is decreased twice after the volume of HPW equal to the nasal cavity volume is delivered into it. Continuous dilution can be represented as dilution in small steps $(\mathrm{dt})$. After the maximum amino acid concentration $\left(n_{0}\right.$ is the number of stimulus molecules) in the nasal cavity was attained, the water that entered the nasal cavity (constant volume $V$ ) at the rate $\phi=18 \mathrm{ml} / \mathrm{min}$ diluted the amino acids. The sequentially decreased concentrations at each dilution step were calculated using the number of amino acid molecules multiplied by the dilution factor $R$ where $R$ is the flow rate $(\phi)$ divided by the volume $(V)$ :

$n_{1}=n_{0}-n_{0} \cdot R \cdot \mathrm{dt}=n_{0} \cdot(1-R \cdot \mathrm{dt})$

where $n_{1}$ is the number of amino acid molecules after the first dilution step and

$n_{2}=n_{1}-n_{1} \cdot R \cdot \mathrm{dt}=n_{0} \cdot(1-R \cdot \mathrm{dt})^{2}$

$n_{2}$ is the number of amino acid molecules after the second dilution step.

After $n$ steps $(t=n \cdot \mathrm{dt})$, number of amino acid molecules in the nasal cavity decreased exponentially:

$n_{t}=n_{0} \cdot(1-R \cdot \mathrm{dt})^{n}$

$n_{t}$ is the number of amino acid molecules after $n$ dilution steps.

Deriving Eq. 3 yields:

$n_{t}=n_{0}\left(1-\frac{\phi \cdot t}{V} \cdot \frac{1}{n}\right)^{n}$
The continuous amino acid wash-out is simulated by an infinite number of dilution steps corresponding to the limit in Eq. 4 as $n$ approaches infinity. Deriving the limit yields:

$n_{t}=n_{0} \cdot e^{-\frac{\phi \cdot t}{V}}$

Equation 5 describes the exponential decrease in the number of stimulus molecules $\left(n_{t}\right)$ in the nasal cavity at time $t$ after the end of its delivery.

The calculations can be used to estimate the duration of suprathreshold stimulus concentration for an individual ORN that is limited by the time of stimulus onset, the duration of the continuous stimulus delivery $(1.7 \mathrm{~s})$, and the dilution of the stimulus in the nasal cavity after the end of its delivery (Fig. 2 A, B). The $n_{t}$ depends on the volume of the nasal cavity and on the water flow through it.

\section{Recording of action potentials}

Action potentials from ORNs were recorded extracellularly with low-impedance $(\sim 1 \mathrm{k} \Omega$ ), metal-filled (Bi 49\%, In $21 \%$, $\mathrm{Pb} 18 \%$, and $\mathrm{Sn} 12 \%$, MaTeck Material-Technologie \& Kristalle $\mathrm{GmbH}$ ) glass microelectrodes, tip-plated with platinum-black (ball diameter 3-5 $\mu \mathrm{m}$ ) [17, 23]. The recorded electrical activity was AC amplified (Grass P-5 Series, amplification $\times 5,000$, band pass $10-3,000 \mathrm{~Hz}$ ), displayed on an oscilloscope and monitored aurally. The action potentials were stored on an audio channel of a VHS cassette. An electrically driven micromanipulator (MS 314, Hugo Sachs Elektronik) enabled a stepwise approach of the tip of the electrode toward the epithelium. Since the ORN response specificities to amino acids across the different lamellae of the olfactory organ were nearly the same in the channel catfish [10], the neural responses were recorded from the easily accessible first to fifth rostral lamellae. An equimolar mixture of the ten amino acids used in this study served as the search solution to determine responsive regions of the lamella. When an ORN response was detected, the electrode position was adjusted to obtain action potentials greater than $200 \mu \mathrm{V}$. Intervals between consecutive stimulus applications were $1.5 \mathrm{~min}$ for $10^{-4} \mathrm{M}$ amino acids and $1.0 \mathrm{~min}$ for $10^{-5}-10^{-8} \mathrm{M}$ amino acids.

\section{Recording the electro-olfactogram}

In parallel with the recording of single unit activity, the EOG was recorded using $\mathrm{Ag} / \mathrm{AgCl}_{2}$ electrodes connected to Ringer's-agar filled glass pipette. The bridge (tip diameter $150 \mu \mathrm{m})$ of the active EOG electrode was positioned $\sim 1 \mathrm{~mm}$ above the olfactory epithelium; the reference electrode was pressed against the skin of the animal caudal to the olfactory organ. The EOG was DC-amplified (10$100 \times$, Grass P18D), displayed on an oscilloscope and a pen-recorder. Signals were digitized (sampling rate $44 \mathrm{kHz}$, 
NeuroCorder D-890, Neuro Data) and stored on the video channel of the video cassette. A second audio channel of the VHS cassette was used for a verbal description of the procedure. The ORN activities and the digitized EOG data were copied off-line onto a PC using a SW-DAQ interface (sampling rate $44.1 \mathrm{kHz}$; National Instruments).

\section{Data analysis}

Electrical responses of ORNs were analyzed for $15 \mathrm{~s}$ before and $30 \mathrm{~s}$ following the onset of stimulus delivery. Only data from the ORNs recordings that lasted $>13 \mathrm{~min}$ and whose responses to the mixture of ten amino acids did not change during the tests were evaluated. The "Neuro Event Manager" software [2] enabled a selection of action potentials evoked by the same ORN based on the slope of the rising phase, the magnitude, and duration of each action potential. Initially the action potentials were superimposed and viewed in $50 \mathrm{~ms}$ time bins on a computer screen to visually confirm single cell identity. Subsequently, the action potentials were replaced with events and the times of their occurrence stored digitally. Interspike intervals and response durations were determined for each ORN. An additional criterion for single unit discrimination was the duration of the interspike interval that should be longer than the relative refractory period $(5 \mathrm{~ms})$. Action potential frequencies were evaluated with the "cumulative slope analysis" method [5]. Briefly, the slope of the cumulative distribution function depends on the frequencies of events. The local linear regression, calculated for five sequential events, was used to determine the local slope of the cumulative distribution function. For the phasic part of the phasic-tonic ORN response to amino acids, the maximal frequency of action potentials (the highest frequency during five action potentials of the phasic response) was determined during the initial $450 \mathrm{~ms}$ of the response; for determining the tonic activity, the median tonic frequency was analyzed during 500-1,500 ms of the response. Single unit identity was verified in experiments using an equimolar mixture of ten amino acids. For tonic only and for phasic-tonic neurons, frequencies of action potentials during the tonic response of a single ORN should be the same for the mixture and for its components, whereas simultaneous response of two ORNs would produce a higher than saturated tonic frequency.

\section{Results}

Testing olfactory organ function in HPW

EOG signals were measured in parallel with single unit activities from 57 olfactory organs of black bullhead catfish. In HPW, the olfactory organs responded to amino acids for more than $6 \mathrm{~h}$ (Fig. 1a). As shown for $10^{-4} \mathrm{ML}-$ Met, the shape of the recorded EOG response to amino acids did not change during the 6-h recording. In HPW, the relative EOG magnitude of neutral amino acids and L-Pro correlated significantly with their relative EOG magnitudes in the TW (Figs. 1b, c; $R=0.94, p<0.001$; data for TW from [61]); however, the basic amino acids, $\mathrm{L}-\mathrm{ArgHCl}$ and $\mathrm{L}-$ Lys $\mathrm{HCl}$, resulted in approximately twice as large EOG magnitudes in HPW than in TW. The dose dependence of the EOG response in HPW was determined for L-nVal that stimulated most of the ORNs tested and was one of the two most stimulatory amino acids. Based on the response to $10^{-4} \mathrm{ML}$-Ala (standardized to 1.0 ), the maximum relative response magnitude to $\mathrm{L}-\mathrm{nVal}$ was 1.06 at $10^{-4} \mathrm{M}, 0.89$ at $10^{-5} \mathrm{M}, 0.59$ at $10^{-6} \mathrm{M}$, and 0.44 at $10^{-7} \mathrm{M}$ concentration, and a similar dose dependence was observed in the TW. Similar to the EOG, single ORNs that lacked spontaneous activity responded to amino acids up to $6 \mathrm{~h}$ after the onset of the HPW perfusion.

\section{ORNs that lack spontaneous activity}

In 117 ORNs that lacked spontaneous activity, we determined the number of action potentials during the entire periods before and between stimulations. The frequency of action potentials $30 \mathrm{~s}$ before 1,228 amino acid stimulations was $0 \mathrm{~Hz}$, which justified the definition: cells that lack spontaneous activity or spontaneously inactive cells.

\section{Dose dependence of ORNs' responses}

\section{Response threshold}

Twenty-one ORNs were tested with $10^{-8} \mathrm{M}$ to $10^{-4} \mathrm{ML}$ nVal (Figs. 2, 3, 4, and 5). Two ORNs responded to $10^{-7} \mathrm{M}$ L-nVal, whereas thresholds for other tested ORNs with LnVal were $10^{-6}(N=8), 10^{-5}(N=7)$, and $10^{-4} \mathrm{M}(N=4$; Fig. 2). During responses to high amino acid concentrations, an initial fast increase in the spike amplitudes was observed during the onset of the phasic response, which was followed by a period of steady spike amplitude (Fig. 3). Toward the end of the tonic activity, a progressive decrease in the spike amplitudes was observed that accompanied the stimulus concentration and spike frequency decrease.

\section{Response frequency}

Nine of the $21 \mathrm{~L}-\mathrm{nVal}$ ORNs responded with tonic activities at all tested concentrations (Fig. 4). Their median frequencies of action potentials in response to $10^{-6}, 10^{-5}$, and $10^{-4}$ ML-nVal were 15, 16, and $17 \mathrm{~Hz}$, respectively (Fig. 6c). In 
Fig. 1 L-Methionine evoked approximately equal amplitudes of EOG 1 (light gray), 3 (dark gray), and $5 \mathrm{~h}$ (black) after the onset of highly purified water $(H P W)$ perfusion (a). Amino acid responses are shown in the decreasing order of magnitude of the relative EOG responses (relative L-Ala) at their $10^{-4} \mathrm{M}$ $\left(10^{-2} \mathrm{M}\right.$ for L-Pro) concentrations in the dechlorinated TW (b) and HPW (c). Control stimulus was either TW or HPW, respectively a

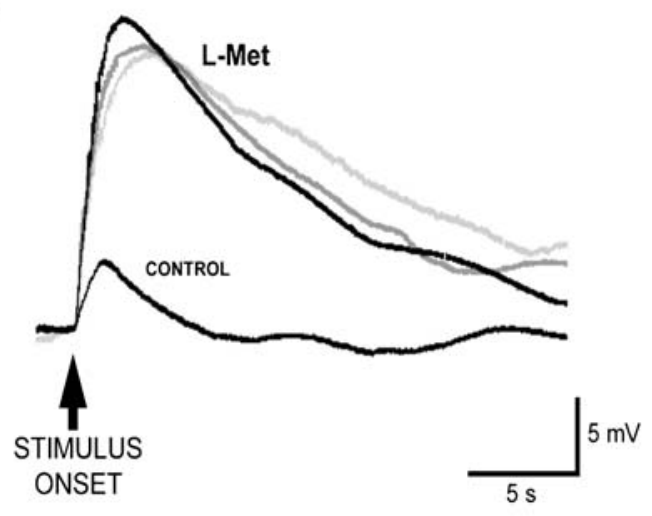

b

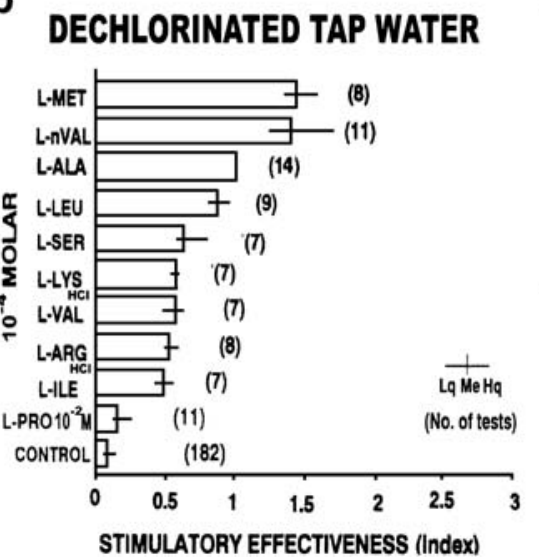

C

HIGHLY PURIFIED WATER

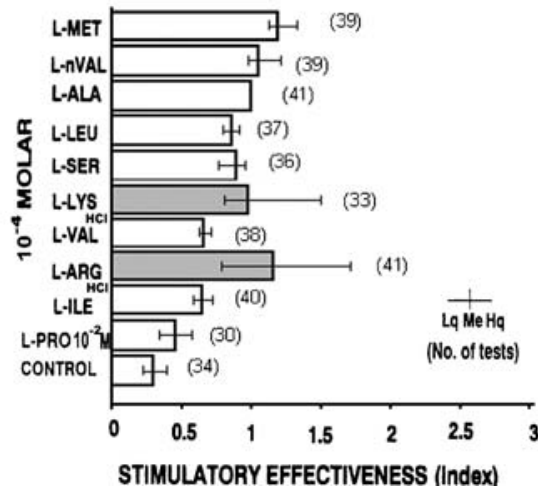

contrast, 12 of 21 ORNs responded to $10^{-4}$ ML-nVal with both phasic and tonic activities consisting of an initial highfrequency burst that lasted $50-450 \mathrm{~ms}$ and a subsequent tonic activity lasting several seconds (Fig. 5). At $10^{-4} \mathrm{ML}-$ $\mathrm{nVal}$, the median phasic response frequency of 12 tested ORNs was $68 \mathrm{~Hz}$ (Fig. 6a) and a median tonic frequency was $19 \mathrm{~Hz}$ (Fig. 6b). At $10^{-5} \mathrm{M}$, the same stimulus evoked a median phasic response frequency of $52 \mathrm{~Hz}$, whereas the median tonic frequencies did not significantly differ to that evoked by the higher L-nVal concentration (Mann-Whitney rank sum test). At micromolar concentrations, two ORNs responded to L-nVal with phasic-tonic activities (54 and $21 \mathrm{~Hz}$ median phasic and tonic frequencies, respectively; Fig. $6 a, b)$. At L-nVal threshold concentrations $\left[10^{-7} \mathrm{M}(N=\right.$
Fig. 2 Decreases of amino acid concentrations in nasal cavities of small (filled circles) and large (empty circles) black bullhead catfish $(A)$. Calculated decreases in amino acid concentrations in the nasal cavities of large catfish after delivery of four different amino acid concentrations $(B)$. After stimulation with L-nVal at four different concentrations, dose-dependent responses are shown as medians and interquartile range of the EOG response durations (dots and thin lines). Predictions for the EOG response durations are based on the durations of the suprathreshold amino acid concentrations

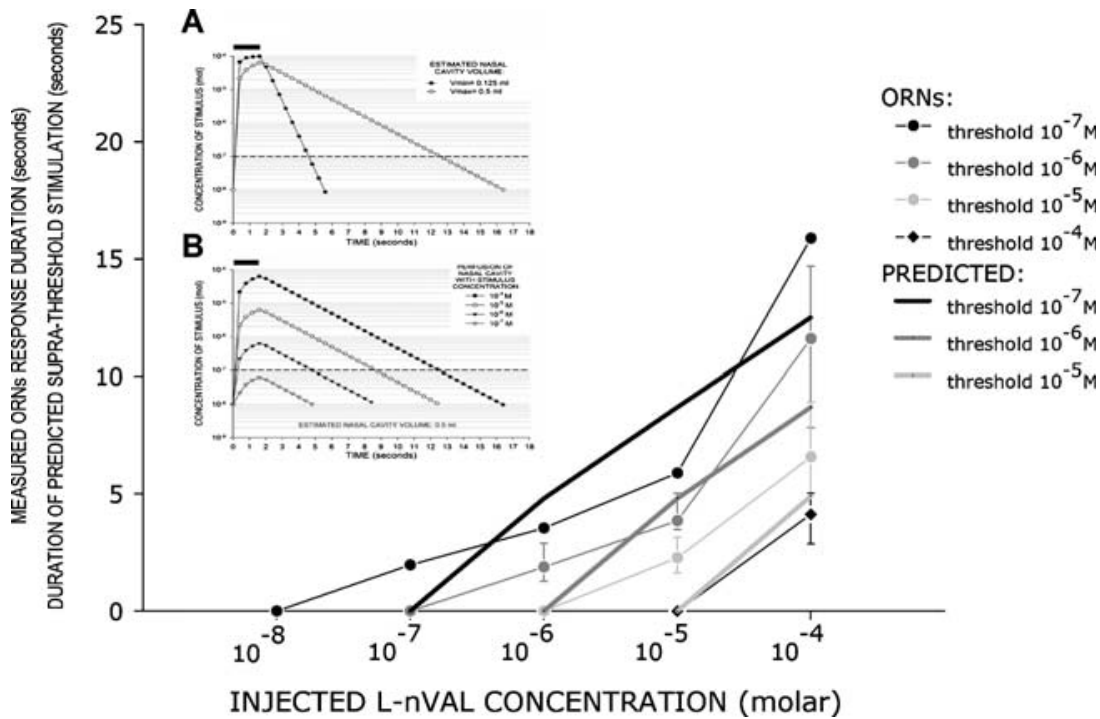




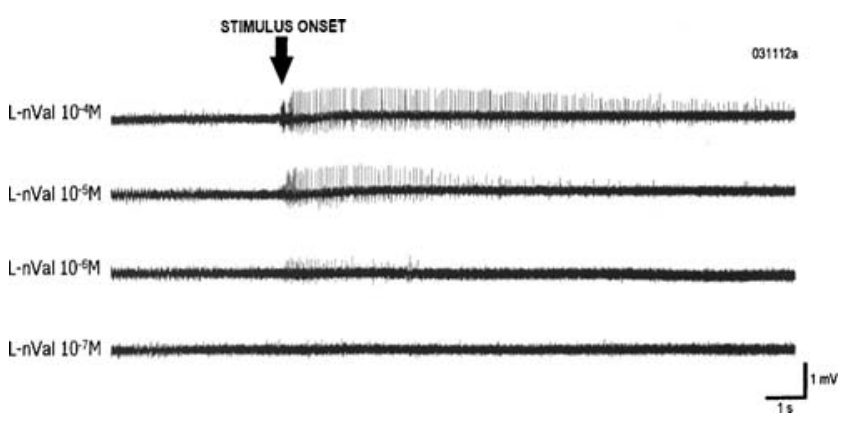

Fig. 3 Band-pass-filtered $(10-3,000 \mathrm{~Hz})$ original recordings of dosedependent responses of specialized ORN to L-nVal. Most action potentials are from the same ORN, and the two large amplitude action potentials are potentially from a different ORN

2); $\left.10^{-6} \mathrm{M}(N=4) ; 10^{-5} \mathrm{M}(N=1) ; 10^{-4} \mathrm{M}(N=1)\right]$, most neuron responses were tonic only, whereas in few ORNs, the response near threshold concentrations consisted of phasic and tonic events $\left[10^{-6} \mathrm{M}(N=2) ; 10^{-5} \mathrm{M}(N=2)\right]$.

L-Met was the second most stimulatory amino acid tested in the bullhead catfish. We assessed dose dependence of six L-Met best ORNs. These ORNs showed either tonic $(N=2)$ or phasic-tonic $(N=4)$ activities. At $10^{-4}$ ML-Met, the tonic response frequencies were 19 and $14 \mathrm{~Hz}$, respectively. ORNs that responded to $10^{-4} \mathrm{ML}-\mathrm{Met}$ with phasic-tonic activities had maximum phasic action potential frequency of $85 \mathrm{~Hz}$ and their median tonic frequency was $\sim 21 \mathrm{~Hz}$. The most sensitive ORNs responded to $10^{-6}$ and $10^{-7}$ ML-Met concentrations with bursts of 22 and $23 \mathrm{~Hz}$ activities, respectively.

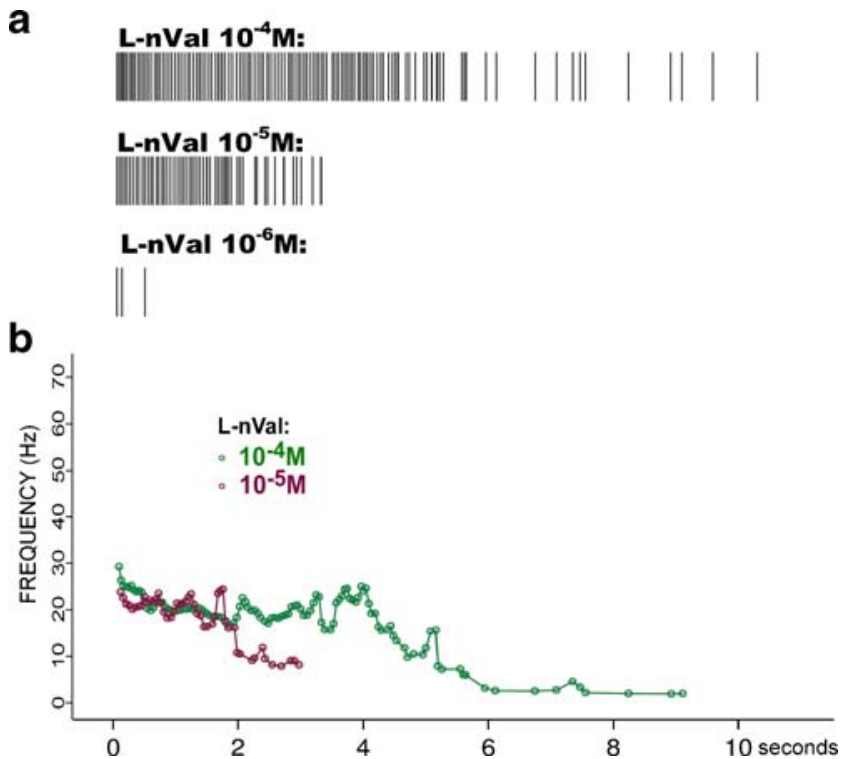

Fig. 4 Action potential times during dose-dependent tonic ORN responses at three different $\mathrm{L}-\mathrm{nVal}$ concentrations (a) and frequencies of action potentials at two L-nVal concentrations (b)

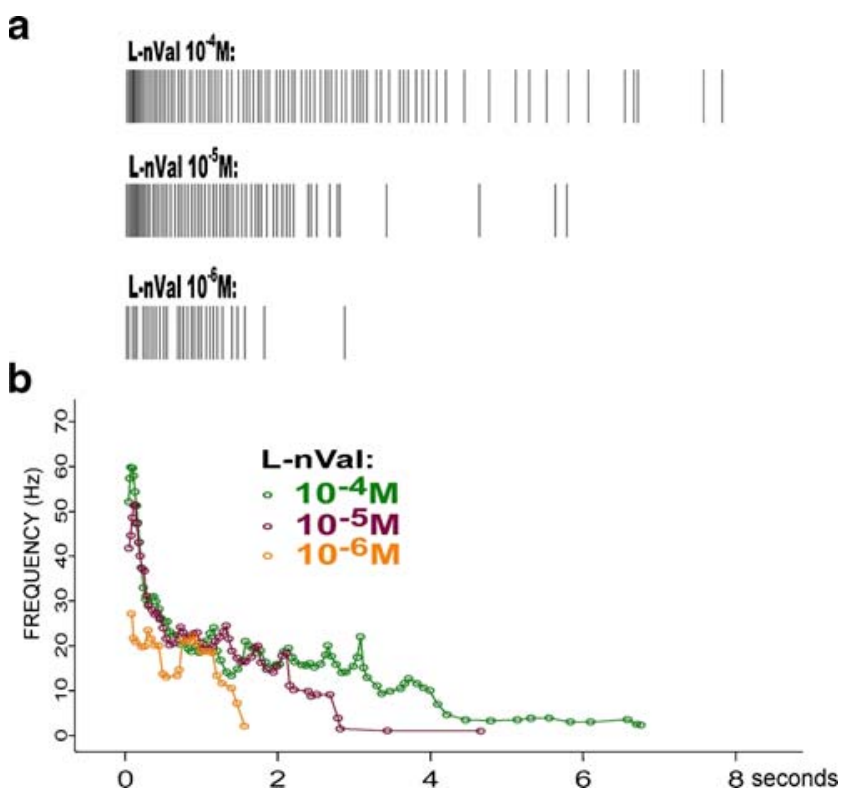

Fig. 5 Action potential times during dose-dependent L-nVal responses of phasic-tonic ORN at three different L-nVal concentrations (a) and frequencies of action potentials at three different L-nVal concentrations (b)

Duration of electrophysiological response enables determination of ORNs specificity

Since the frequency of ORN tonic responses saturated over a single log concentration unit, we did not find it useful for concentration dependence descriptor over several log concentration units. Without correlation between stimulus concentration and frequency during the tonic response, the only common property of phasic-tonic and tonic only ORNs responses that correlates with concentration is the duration of the entire physiological response (Figs. 2, 3, 4, and 5, see the "Discussion" section). For ORNs that respond to the same stimulus, the duration of the electrophysiological response differed depending upon the duration of the suprathreshold stimulus. Following an application of a stimulus solution, its concentration increased as determined by the ratio between its injected volume and volume of the nasal cavity, and it decreased exponentially with time as water diluted the stimulating solution in the nasal cavity. The nasal cavity volume in our experiments was estimated to be between 0.125 and $0.5 \mathrm{ml}$ for the smallest and largest catfish, respectively (Fig. 2 A). For the most sensitive ORNs, the threshold for L-nVal was $10^{-7} \mathrm{M}$. After application of $10^{-4} \mathrm{ML}-\mathrm{nVal}$, its concentration remained above $10^{-7} \mathrm{M}$ during 4.8 and $12.6 \mathrm{~s}$ in the smallest and largest olfactory organs tested, respectively (Fig. 2 A). For the largest catfish studied, delivery of $10^{-4}$, $10^{-5}$, and $10^{-6} \mathrm{M}$ stimuli resulted in $>10^{-7} \mathrm{M}$ concentration within the nasal cavity for $\sim 12.6, \sim 9$, and $\sim 5 \mathrm{~s}$, respectively (Fig. 2 B). Durations of the ORNs responses recorded in 
Fig. 6 Median action potential frequencies and their interquartile range during phasic (a) and tonic (b) activities of the phasictonic ORNs and median action potential frequencies of tonic ORNs (c) during stimulation with three different amino acid concentrations $(* p<0.05$, Mann-Whitney rank sum test)
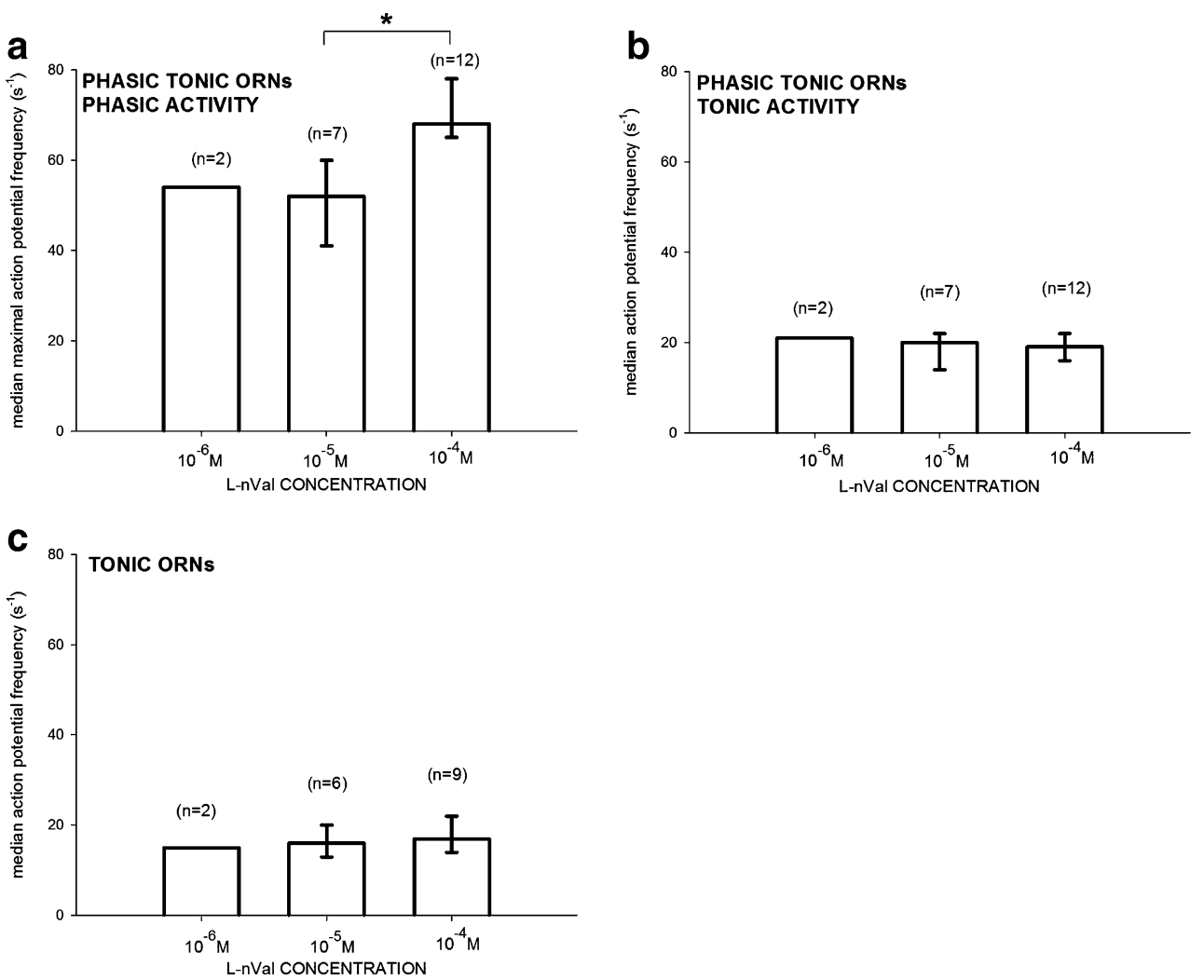

this study were $10-22 \mathrm{~s}$ at $10^{-4} \mathrm{M}, 5-7 \mathrm{~s}$ at $10^{-5} \mathrm{M}$, and 3$4 \mathrm{~s}$ at $10^{-6} \mathrm{M}$ concentration of $\mathrm{L}-\mathrm{nVal}$. Except for the expected variability derived from differences in nose volumes, it is fascinating that the durations of electrophysiological responses approximately equaled the predicted durations of the suprathreshold amino acid stimulation (Fig. 2). Due to different nasal cavity volumes, the differences in the durations of the suprathreshold amino acid concentrations could be up to three times (Fig. 2 A).
ORNs’ response specificities

We identified ORN specificities by the greatest durations of their responses to amino acid at $10^{-4} \mathrm{M}$ concentration $\left(10^{-2}\right.$ $\mathrm{M}$ for L-Pro; Fig. 8). Thirteen ORNs were excited by a single amino acid, either L-nVal $(N=7)$, L-Met $(N=4)$, or LAla $(N=2$; Fig. 8a). Most ORNs sampled $(N=17 ; 39 \%)$ were excited by two amino acids, L-nVal and L-Met (Figs. 7 and $8 \mathrm{~b}$ ). Their response duration to $10^{-4} \mathrm{ML}-\mathrm{nVal}$ (5.8-
Fig. 7 Band-pass-filtered (10$3,000 \mathrm{~Hz}$ ) original recordings of an ORN responding to L-nVal and L-Met and its electrophysiological response to the mixture of these two amino acids at $10^{-4}$ $\mathrm{M}$ concentration. Most action potentials during the continuous train are from the same ORN, and the action potentials after the end of the continuous train potentially originate from different ORNs

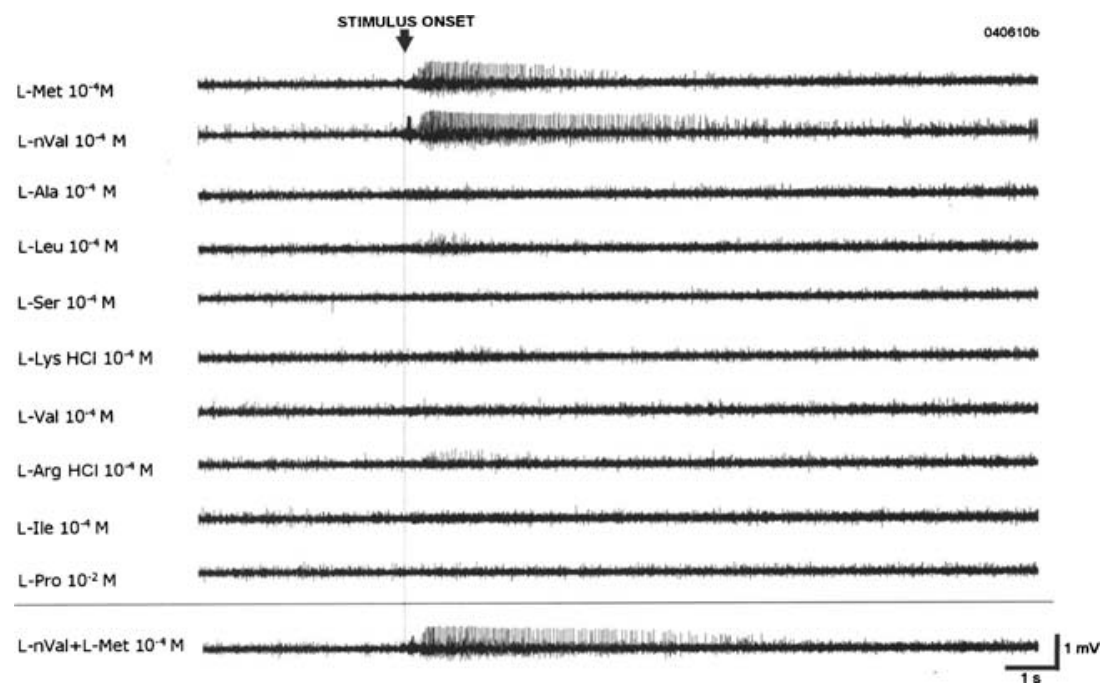


Fig. 8 Response specificities of 44 ORNs. Using EOG stimulatory efficiency sequence (d) for ORNs that responded to single amino acid (a), ORNs that responded to two amino acids

(b), and ORNs that responded to $>2$ amino acids (c) a

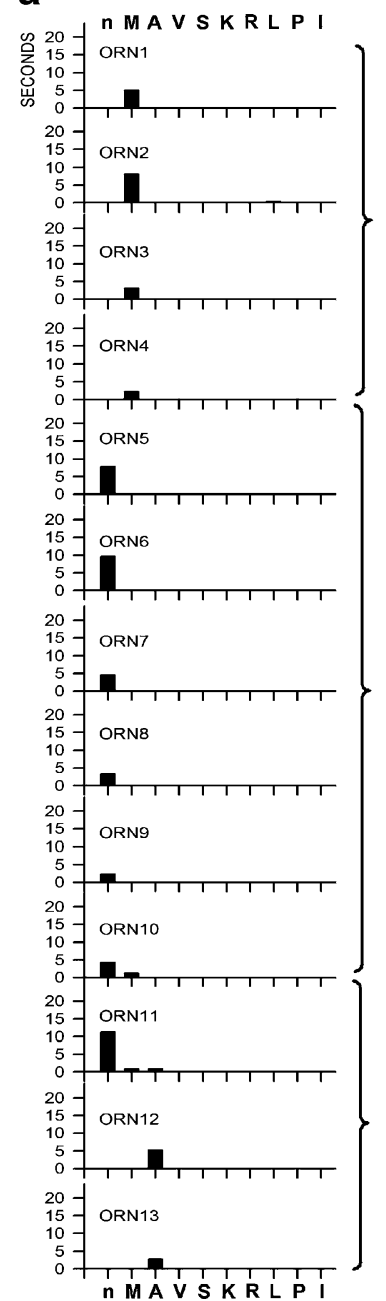

b

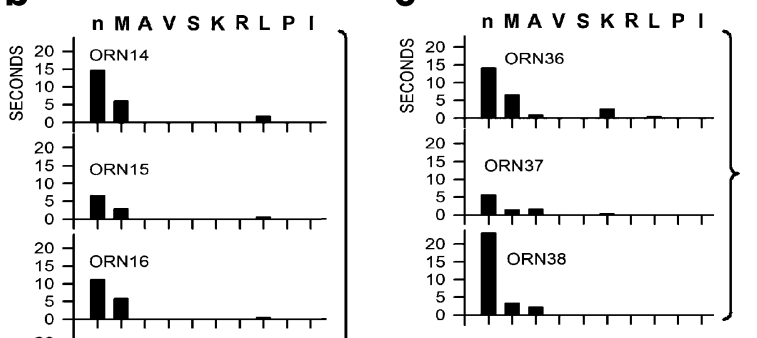

ORN17

$10-10$

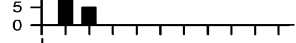

$20-15-$

ORN18

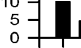

$15-$ ORN19

5
0

$20-15$ ORN20

正

$20-$ ORN21

$10-1$

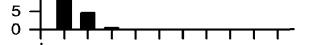

ORN22

1.

- ORN23

(1)

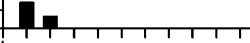

ORN24

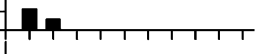

ORN25

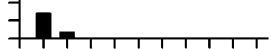

15 - ORN26

1, 1, Tा

ORN27

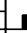

$20-1$
$10-1$

ORN28

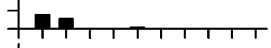

- ORN29

-

$20-$

ORN30

$5-$

$20-15$

15 ORN31

$5-$

20 ORN32

$10-$

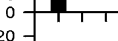

ORN33

$10-1$

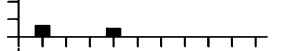

ORN34

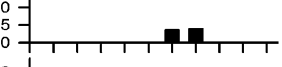

$15-1$

ORN35

ORN35

nMAVSKRLP
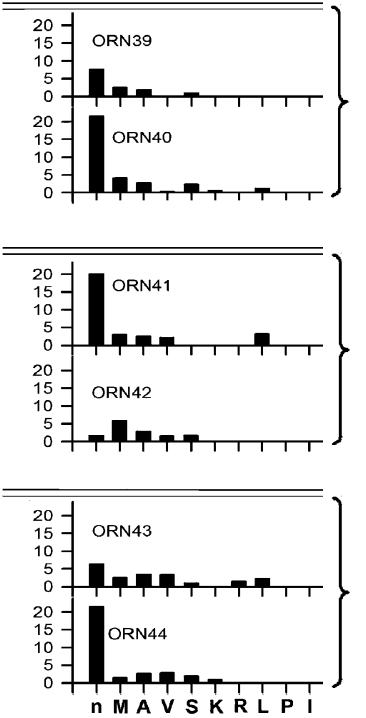

d

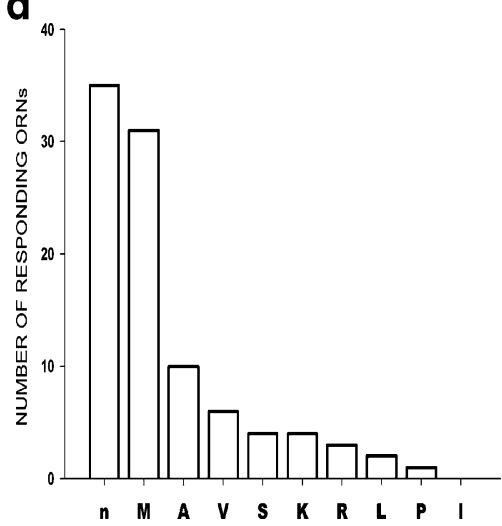


$14.7 \mathrm{~s} ; N=12$ ) was at least twice the duration of the responses to L-Met $(1.7-6.1 \mathrm{~s})$. Only one ORN responded best to L-Val $(10.8 \mathrm{~s})$ as its response duration was twice longer than that to $\mathrm{L}-\mathrm{nVal}$. In a single ORN, the response durations to L-Val and L-nVal were almost equal. Two of 44 ORNs responded best to $\mathrm{L}-\mathrm{ArgHCl}$ and $\mathrm{L}-\mathrm{LysHCl}$, and the response durations were 3.6 and 3.9 and 1.6 and $1.7 \mathrm{~s}$, respectively. In one ORN, L-Pro triggered a long response (20.9 s), whereas its response to L-Met was short (5.6 s). Nine of 44 ORNs responded to three to six amino acids (Fig. 8c). Out of these neurons, only one ORN responded with greater response duration to L-Met than to L-nVal; this neuron was also excited by L-Ala, L-Val, and L-Ser. Most cells that were excited by more than one amino acid (including L-nVal) responded longest to only one amino acid ( $N=27$; Fig. $8 \mathrm{~b}, \mathrm{c})$. The response to the most effective stimulus, usually L-nVal, was at least twice longer than that to the second best amino acid. Since L-nVal is not a natural amino acid, we consider L-nVal and L-Met responding ORNs as specialized L-Met neurons (Fig. 8b, c).

\section{Spontaneously active ORNs in HPW}

In addition to those ORNs that lacked spontaneous activity and were activated by amino acids, spontaneously active ORNs that were suppressed by amino acids were observed in HPW in great numbers. To confirm the normal function of the olfactory organs in HPW, responses to amino acids of a few spontaneously active ORNs were recorded and compared to those obtained in the TW [7, 47]. In most cases, irregular suppressive responses to amino acids were observed in spontaneously active ORNs in HPW. Only one neuron responded with dose-dependent suppression to all ten tested amino acids. In this neuron, the frequencies of action potentials during spontaneous activity were between 14 and $23 \mathrm{~Hz}$; their spike frequency during suppression was 0-4 Hz.

\section{Discussion}

Bathing olfactory organ in HPW enables detection of the spontaneously inactive ORNs

In previous studies of freshwater teleost ORNs, investigators bathed the olfactory organs with TW while measuring responses to chemical stimuli [7, 9, 17, 34, 35, 44]. Using the TW as bathing medium produces specific recording conditions. Ions diffuse from the 4-10 $\mu \mathrm{m}$ thick mucus covering the olfactory cilia and microvilli into the surrounding water within less than a hundred milliseconds [31]. Therefore, the ohmic resistance of the freshwater fish mucus is likely the same as that of TW $(\sim 1 \mathrm{k} \Omega \mathrm{cm})$. At such low resistances, volume conductors like TW compress the electric field equipotential surfaces around the apical portions of the ORNs. In TW, if the electrode is more than a few micrometers above the olfactory cilia and microvilli, the cell's activities cannot be detected by the electrode.

In TW, an electrode nearby an ORN or in direct contact with it detects its action potentials, thus making it "visible" to the physiologist. In the present study, responses of single ORNs of black bullhead catfish (A. melas) were recorded during amino acid stimulation while bathing the olfactory organ with HPW. HPW has an ohmic resistance of $>18.2 \mathrm{M} \Omega \mathrm{cm}$ and contains $\sim 1,000 \times$ fewer ions than the artificial pond water $[11,36,42]$. The ratio of ohmic resistances between HPW and TW is approximately 10.000 . The size of electric potential is inversely proportional to the cube of the distance between the cell and recording electrode and proportional to ohmic resistance of the medium [29]. Therefore, the electrode could be positioned at roughly $20 \times$ the TW distance from the neuron and still record large magnitude action potentials. When compared to TW, this greatly increased the chances of detecting amino acid responses of ORNs lacking spontaneous activity. The test that used the search solution of ten equimolar amino acids in HPW revealed a presence of numerous spontaneously inactive neurons responding to amino acids that were detected as multiunit responses. To allow single unit identification and avoid multiunit detection, locations at the edge of olfactory receptive fields, where density of ORNs is lower, had to be selected. Numerous spontaneously active cells were also detected; however, in the search for inactive neurons responsive to amino acids, the former cells were not tested further. Thus, the ratio between spontaneously inactive and spontaneously active ORNs remained unknown.

\section{Testing olfactory organ function in HPW}

Amino acids, potent olfactory cues for aquatic animals [57], evoke EOGs that differ in peak magnitude depending upon their stimulatory effectiveness. In black bullhead and channel catfishes, L-nVal and L-Met are potent olfactory stimuli, whereas Gly and L-Pro are relatively poor stimuli [7, 9, 61]. In freshwater fishes, basic amino acids are generally intermediate in effectiveness. Relatively large EOG responses to L-Met were observed in the zebrafish [44] and in the marine catfish, Ariopsis felis (formerly Arius felis) [8].

The present study indicated that the stimulatory effectiveness of neutral amino acids and L-Pro in HPW and TW were highly correlated $(R=0.94, p<0.05$; Fig. $1 \mathrm{~b}, \mathrm{c})$. In both media, the largest EOG magnitudes were evoked by LMet and L-nVal, and a minimal EOG occurred in response to L-Pro; however, the magnitudes of the responses to the basic amino acids were significantly enhanced in HPW 
(Fig. 1b, c) compared to TW. The large EOG magnitude to the basic amino acids did not reflect the numbers of ORNs excited by either of these two stimuli as only four of 44 ORNs studied were excited by the basic amino acids (Fig. 8d). For comparison, 35 of these 44 neurons were excited by the neutral amino acid, L-nVal. The high correlation between the magnitudes of the EOG recorded in HPW and in TW indicates that, except for $\mathrm{L}-\mathrm{ArgHCl}$ and L-Lys $\mathrm{HCl}$, the relative olfactory responses to amino acids did not depend on external ion concentrations.

Based on studies in land vertebrates, it is generally believed that receptor currents in ORNs flow through ion channels located on cilia and microvilli $[20,38]$. Due to the extremely low ion concentrations in HPW that removes ions by diffusion from the mucus, receptor currents through ciliary membrane cannot be substantiated in freshwater fish in HPW. What could be the mechanism of ORN's depolarization in freshwater fish in a nearly total absence of ions in mucus and HPW? Receptor cell depolarization in an environment with little or no ions can either be provided by the outward $\mathrm{Cl}^{-}$currents on cilia [53] or by inward $\mathrm{Na}^{+}$ currents on dendrite and soma of the receptor cell below the tight junctions. Theoretically, through the membrane of cilia and microvilli, neither $\mathrm{Na}^{+}$nor $\mathrm{K}^{+}$could depolarize olfactory receptor cell since the reversal potentials between intracellular solution and HPW for these ions [4] are minus several hundred millivolts. In goldfish and chum salmon olfaction, $\mathrm{Ca}^{++}$or $\mathrm{Na}^{+}$concentrations in the surrounding medium did not influence receptor potentials [30, 54]. In our experiments, the concentrations of $\mathrm{K}^{+}, \mathrm{Ca}^{++}$and $\mathrm{Mg}^{++}$in the water flowing out the olfactory cavity was nearly the same as in the water entering the cavity, indicating that few cations were lost from the olfactory lamellae during the experiment. Since there was no loss of olfactory function in the HPW during 6-h experiments, receptor currents most probably occur below the tight junctions.

Dose dependence of ORNs' responses

\section{Response threshold}

Olfactory thresholds to the more potent amino acids in both channel and black bullhead catfishes are in the nano- to micromolar range [7, 47, 60, 61]. In the present report, we observed similar thresholds for L-nVal, a potent amino acid for most of the tested ORNs that lacked spontaneous activity $\left(10^{-4}-10^{-6} \mathrm{M}\right)$, whereas the most sensitive ORNs responded to $10^{-7} \mathrm{ML}-\mathrm{nVal}$ (Fig. 2). Differential thresholds for the same amino acid in different ORNs support the recruitment hypothesis of the EOG dose-response relationships $[15,37,45]$. The hypothesis states that at low concentrations the most sensitive neurons respond to a stimulus (L-nVal) and at higher concentrations the less sensitive neurons are recruited successively. It is extremely important to point out that each ORN responded dose dependently with either tonic or phasic-tonic activities dependent only on its sensitivity for the specific amino acid. All these responses were robust and at concentrations 100 times above threshold contained $>100$ action potentials. This is substantially different from the mechanisms proposed for frog ORNs [13] where minute ORNs' responses summate after convergence to mitral cells to produce a depolarization triggering action potentials.

\section{Response frequency}

In fish and land vertebrates, EOG dose-response relationships are relatively shallow; in catfish, an approximately 5 log unit change in stimulus concentration evokes $1 \log$ unit change in EOG magnitude [7,61]. In contrast, the doseresponse relationships of single ORNs are very steep in mice [6], tiger salamander [19, 25], frog [50], zebrafish [39], rainbow trout [27] as well as bullhead catfish. We studied dose dependence of responses to L-nVal in 21 ORNs that lacked spontaneous activity (Figs. 2, 3, 4, and 5). ORNs responded either with tonic (57\% of ORNs, Fig. 4) or, like in salamander ORNs [25, 26], with phasic and tonic activities (Fig. 5). At L-nVal concentrations that were $>10 \times$ above the ORNs' threshold, the initial frequency of the tonic response saturated at $17-21 \mathrm{~Hz}$ (Fig. 6). During the tonic portion of the response, a further increase in stimulus concentration did not significantly influence the frequency of action potentials. In contrast, the phasic responses of phasic-tonic neurons were at least in part dose dependent (Fig. 6a) and did not saturate even at L-nVal concentrations that were $>1,000 \times$ above threshold. Similar dose dependence was observed for L-Met. It is plausible that the short $(450 \mathrm{~ms})$ large amplitude depolarizations of bullhead catfish phasic-tonic ORNs contribute to the initial large amplitude EOG [18], whereas the later smaller amplitude EOG is composed of the ORNs' receptor potentials during their tonic activities.

Response duration of the tonic activity and amplitude of action potentials

Electrophysiological responses of salamander ORNs did not adapt during prolonged stimulation as the duration of the responses closely followed the stimulus duration [26]. Similarly, in bullhead catfish, the duration of ORNs tonic responses to L-nVal $(N=21)$ were concentration dependent over several units of log concentration (Figs. 2, 3, 4, and 5). The maximum duration of the phasic response was $\sim 450 \mathrm{~ms}$ in all phasic-tonic ORNs, whereas the duration of the tonic responses increased with stimulus concentration (Figs. 2, 3, 4, and 5). 
During the onset of the phasic response, action potential amplitude rapidly increased, whereas it slowly decreased during the fading of the tonic response (Figs. 3 and 7). This phenomenon cannot be explained by a change in conductance of the medium between recording electrode and ORN since the concentration gradients between inside and outside the cells drive ions toward HPW. During onset of the response, any transient leakage of ions, even below the detection level, would result in transient action potential amplitude decrease rather than its increase. Similar to salamander [59] and unlike frog [13], it seems likely that during the initial depolarization phase of the olfactory response the voltage-gated currents increased, whereas they decreased during the slow repolarization of the ORNs.

\section{ORN response specificity}

In mice and rats, heterologous expression of olfactory receptor proteins revealed their narrow binding specificities, binding preferentially a single or few odorants [1, 3, 58, 64]. Assuming a single olfactory receptor protein is expressed in a cell, large binding affinity for one odorant is expected, whereas binding affinities for few other odorants would be low $[1,3,6]$. Unexpectedly, many frog ORNs responded with excitation to several chemically dissimilar stimuli $[15,51]$, which indicated their broad response spectra. Similarly, ORNs of X. laevis tadpoles responded to up to 19 chemically dissimilar amino acids [41].

In the channel catfish, most of the spontaneously active ORNs tested responded to amino acid stimulation with suppression [34, 35]. Few spontaneously active neurons responded to amino acids with excitation [34]. It is extremely difficult to compare channel catfish spontaneously active ORNs response specificities with the response specificities of bullhead catfish spontaneously inactive ORNs. There is a major difference between the two kinds of neurons: The spontaneously inactive ORNs of bullhead catfish are narrowly tuned and respond excitedly to a single natural amino acid, whereas the spontaneously active neurons of channel catfish respond with suppression or excitedly $[34,47]$ to several different amino acids, and the excitatory responses are always to an entire group of amino acids such as short-chain neutral, long-chain neutral, and basic amino acids [47]. The amino acid excitatory thresholds for the channel catfish spontaneously active ORNs were between $10^{-8}$ and $10^{-6} \mathrm{M}$ [47], whereas the most sensitive inactive ORNs of bullhead catfish responded to LnVal with a threshold of $10^{-7} \mathrm{M}$, and the sensitivity of other ORNs for the same amino acid was between $10^{-6}$ and $10^{-4}$ M. Most natural waters, including the tap water, contain single free dissolved amino acids at concentrations up to $\sim 10^{-7} \mathrm{M}[40]$, whereas the HPW was free of amino acids. Thus, one would expect lower amino acid thresholds in the
HPW than in the tap water; however, the number of ORNs' thresholds determined $(N=21)$ was too small to find, among thousands of L-nVal ORNs, the most sensitive L-nVal neurons.

Olfactory bulb [46] and forebrain data [48] that showed predominant excitation during olfactory stimulation predicted predominant ORNs excitation. In unpublished study of Koce et al., the responses of $>555$ spontaneously active ORNs in the black bullhead catfish were suppressive. In most cases, the suppressive responses did not repeat regularly during repeated stimulations, and these responses were mostly not dose dependent. Dose-dependent excitation of the bullhead (Koce et al., unpublished data) and channel catfish [47] ORNs were observed in few spontaneously active ORNs. Spontaneous activities of ORNs that are suppressed during amino acid stimulation could be activities of immature neurons [63]. Amino acid stimulation that triggers a nonspecific suppression in numerous spontaneously active ORNs [47] potentially renders large olfactory bulb areas less active, thus increasing the difference between excited and inactive glomeruli.

Tests of the ten amino acids at $10^{-4} \mathrm{M}$ concentration showed that spontaneously inactive ORNs of the black bullhead catfish are in most cases highly specialized neurons (Fig. 8). Of 44 ORNs studied in detail, 31 (70\%) were most sensitive to L-nVal, and other ORNs were responding best to L-Met $(N=5)$, L-Ala $(N=2)$, L-Val $(N=1)$, and L-Pro $(N=1)$. Their responses to the second best amino acids were small compared to responses to the best amino acid. Only four ORNs responded equally to two

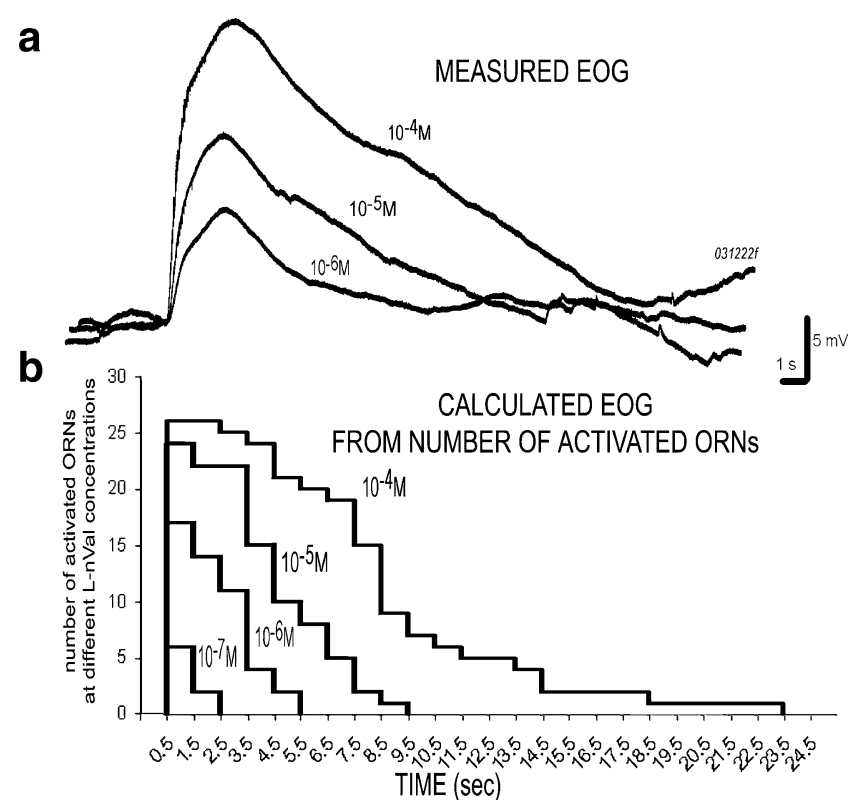

Fig. 9 Comparison of EOG responses at three different L-nVal concentrations (a) compared with numbers of ORNs responding to four different L-nVal concentrations at different times after the onset of stimulation (b) 
amino acid stimuli. Like in goldfish [58], responses of the bullhead ORNs that responded equally well to L-LysHCl and $\mathrm{L}-\mathrm{ArgHCl}$ were suggestive of their similar binding affinities at their receptor molecules. The responses of spontaneously inactive ORNs to amino acids in the black bullhead catfish and excitatory responses of spontaneously active ORNs in the channel catfish [47] are mutually supportive with the excitatory neuron responses in the olfactory bulb [46] and forebrain [48] of the channel catfish; the latter responses are most probably triggered by the ORNs excitatory activity.

The magnitude of EOG and number of ORNs responding to amino acids

In fishes, the EOG, which is the sum of ORN receptor potentials [49], was used as a simple method indicating sensitivity and relative specificity of olfactory organs $[7,56,57,60]$. Prior evidence to support this hypothesis was obtained by the high correlation between EOG magnitude and integrated multiunit responses to amino acid stimuli in the olfactory organs of the channel catfish [7] and eel [55]. Ottoson's hypothesis [49] predicted a significant positive correlation between the number of responding ORNs and EOG magnitude. Differentially sensitive ORNs have different thresholds for the same amino acid (Fig. 2). Cumulative numbers of responding ORNs at different L-nVal concentrations depend on stimulus concentration: 21 ORNs responded to $10^{-4} \mathrm{M}, 17$ ORNs to $10^{-5} \mathrm{M}, 11$ ORNS to $10^{-6}$, and two to $10^{-7} \mathrm{M}$ concentrations of $\mathrm{L}-\mathrm{nVal}$. The numbers of ORNs responding to L-nVal at different concentrations were correlated significantly $(R=0.97, p<0.05)$ with the relative EOG magnitudes. By adding up the numbers of ORNs activated during one second time bins in the dose-response tests of L-nVal, we confirmed the Ottoson hypothesis (Fig. 9). The stepwise curves thus obtained resemble nearly perfectly the EOG curves obtained during the EOG recordings.

To test if EOG magnitude is directly correlated with the number of ORNs activated by different odorants, the number of ORNs excited by specific amino acids tested at $10^{-4} \mathrm{M}\left(10^{-2} \mathrm{M}\right.$ for L-Pro) concentrations were correlated with their relative EOG. Neutral amino acids that evoked large EOG magnitudes (Fig. 1c) also triggered responses in large number of ORNs (Fig. 8d). L-Met and L-nVal that evoked the largest EOG magnitudes triggered electrophysiological response in 32 and 35 ORNs, respectively, whereas L-Pro evoked the smallest EOG and activated a single ORN. Number of spontaneously inactive ORNs that responded to neutral amino acids and L-Pro correlated significantly with their relative EOG magnitudes $(R=0.77$, $p<0.05)[7,55]$, thus reconfirming the Ottoson hypothesis [49].
Acknowledgments We sincerely thank Prof. John Caprio for reading the manuscript and Prof. Andrej Blejec for helping with mathematical procedures. The authors also recognize the contribution of Polonca Razpotnik, Faculty of Chemistry of the University of Ljubljana who analyzed ion concentrations in the highly purified water. This work was supported by the Slovenian Research Agency grant P-141.

Conflict of interest The authors declare that they have no conflict of interest.

Open Access This article is distributed under the terms of the Creative Commons Attribution Noncommercial License which permits any noncommercial use, distribution, and reproduction in any medium, provided the original author(s) and source are credited.

\section{References}

1. Abaffy T, Matsunami H, Luetje CW (2006) Functional analysis of a mammalian odorant receptor subfamily. J Neurochem 97:1506-1518

2. Amon T (1992) A new computer program for neuronal spike data evaluation. Biol Vestn 40(2):1-8

3. Araneda RC, Kini AD, Firestein S (2000) The molecular receptive range of an odorant receptor. Nat Neurosci 3(12):1248-1255

4. Augustine GJ (2001) Neural signaling. In: Purves D (ed) Neuroscience. Sinauer, Victoria, pp 31-184

5. Blejec A (2005) Statistical method for detection of firing rate changes in spontaneously active neurons. Neurocomputing 65-66:557-563

6. Bozza T, Feinstein P, Zheng C, Mombaerts P (2002) Odorant receptor expression defines functional units in the mouse olfactory system. J Neurosci 2(8):3033-3043

7. Caprio J (1978) Olfaction and taste in the channel catfish: an electrophysiological study of the responses to amino acids and derivatives. J Comp Physiol [A] 123:357-371

8. Caprio J (1980) Similarity of olfactory receptor responses (EOG) of freshwater and marine catfish to amino acids. Can J Zool 58:1778-1784

9. Caprio J, Byrd RP (1984) Electrophysiological evidence for acidic, basic, and neutral amino acid olfactory receptor sites in the catfish. J Gen Physiol 84:403-422

10. Chang QH, Caprio J (1996) Electrophysiological evidence for the broad distribution of specific odorant receptor molecules across the olfactory organ of the channel catfish. Chem Senses 21:519-527

11. Christiansen RG, Marshall JM (1965) Study of phagocytosis in the ameba Chaos chaos. J Cell Biol 25:443-457

12. Dionne VE (1992) Chemosensory responses in isolated olfactory receptor neurons from Necturus maculosus. J Gen Physiol 99:415-434

13. Drongelen WV (1978) Unitary recordings of near threshold responses of receptor cells in the olfactory mucosa of the frog. J Physiol 277:42335-4

14. Duchamp A, Revial MF, Holley Leod PM (1974) Odor discrimination by frog olfactory receptors. Chem Senses 1:213-233

15. Duchamp-Viret P, Chaput M, Duchamp A (1999) Odor response properties of rat olfactory receptor neurons. Science 284:2171-2178

16. Duchamp-Viret P, Duchamp A, Chaput MA (2000) Peripheral odor coding in the rat and frog: quality and intensity specification. J Neurosci 20:2383-2390

17. Erickson JR, Caprio J (1984) The spatial distribution of ciliated and microvillous olfactory receptor neurons in the channel catfish is not matched by a differential specificity to amino acid and bile salt stimuli. Chem Senses 9:127-141

18. Evans RE, Hara TJ (1985) The characteristics of elektroolfaktogram (EOG): its recovery following olfactory nerve section in rainbow trout (Salmo gairdneri). Brain Res Amst 330:65-75 
19. Firestein S, Picco C, Menini A (1993) The relation between stimulus and response in olfactory receptor cells of the tiger salamander. J Physiol 468:1-10

20. Flannery RJ, French RJ, Kleene SJ (2006) Clustering of cyclicnucleotide-gated channels in olfactory cilia. Biophys J 91:179-188

21. Friedrich RW, Laurent G (2001) Dynamic optimization of odor representations by slow temporal patterning of mitral cell activity. Science 291:889-894

22. Friedrich RW, Laurent G (2004) Dynamics of olfactory bulb input and output activity during odor stimulation in zebrafish. J Neurophys 91:2658-2669

23. Gesteland RC (1975) Activity in the olfactory epithelium. In: Moulton DG, Turk A, Johnson JW (eds) Methods in olfactory research. Academic, New York, pp 288-305

24. Getchell TV (1973) Analysis of unitary spikes recorded extracellularly from frog olfactory receptor cells and axons. J Physiol 234:533-551

25. Getchell TV, Shepherd GM (1978) Responses of olfactory receptor cells to step pulses of odour at different concentrations in the salamander. J Physiol 282:521-540

26. Getchell TV, Shepherd GM (1978) Adaptive properties of olfactory receptors analysed with odour pulses of varying durations. J Physiol 282:541-560

27. Hara TJ (1982) Structure-activity relationships of amino acids as olfactory stimuli. In: Hara TJ (ed) Chemoreception in fishes. Elsevier Scientific, Amsterdam, pp 135-157

28. Hara TJ (1994) Olfaction and gustation in fish: an overview. Acta Physiol Scand 152:207-217

29. Hobbie RK, Bradley JR (2007) Intermediate physics for medicine and biology. Springer, New York

30. Hubbard PC, Ingleton PM, Bendell LA, Barata EN, Canário AVM (2002) Olfactory sensitivity to changes in environmental $\left[\mathrm{Ca}^{2+}\right]$ in the freshwater teleost Carassius auratus: an olfactory role for the $\mathrm{Ca}^{2+}$-sensing receptor? J Exp Biol 205:2755-2764

31. Jacobs MH (1967) Diffusion processes. Springer, New York

32. Juge A, Holley A, Delaleu JC (1979) Olfactory receptor cell activity under electrical polarization of the nasal mucosa in the frog. I. Spontaneous activity. J Physiol 75(8):919-927

33. Rajon D (1979) Olfactory receptor cell activity under electrical polarization of the nasal mucosa in the frog: II. Responses to odour stimulation. J Physiol 75(8):929-938

34. Kang J, Caprio J (1995) In vivo responses of single olfactory receptor neurons in the channel catfish, Ictalurus punctatus. J Neurophysiol 73(1):172-177

35. Kang J, Caprio J (1997) In vivo responses of single olfactory receptor neurons of channel catfish to binary mixtures of amino acids. J Neurophysiol 77:1-8

36. King CA, Preston TM (1977) Studies of anionic sites on the cell surface of the amoeba Naegleria gruberi using cationized ferritin. J Cell Sci 28:133-149

37. Korsching $S$ (2005) Selective imaging of the receptor neuron population in the olfactory bulb of zebrafish and mice. Chem Senses 30:i101-i102

38. Leinders-Zufall T, Greer CA, Shepherd GM, Zufall F (1998) Visualizing odor detection in olfactory cilia by calcium imaging. Ann N Y Acad Sci 855:205-207

39. Luu P, Acher F, Bertrand HO, Fan J, Ngai J (2004) Molecular determinants of ligand selectivity in a vertebrate odorant receptor. J Neurosci 24(45):10128-10137

40. Lytle CR, Perdue EM (1981) Free, proteinaceous, and humicbound amino acids in river water containing high concentration of aquatic humus. Environ Sci Technol 15(2):224-228

41. Manzini I, Schild D (2004) Classes and narrowing selectivity of olfactory receptor neurons of Xenopus laevis tadpoles. J Gen Physiol 123(2):99-107

42. Marsot P, Couillard P (1979) Action du glutathion sur l'induction de pseudopodes et l'activite locomotrice d'Amoeba proteus. Can J Zool 57:465-468
43. Mathews DF (1972) Response patterns of single neurons in the tortoise olfactory epithelium and olfactory bulb. J Gen Physiol 60:166-180

44. Michel WC, Lubomudrov LM (1995) Specificity and sensitivity of the olfactory organ of the zebrafish, Danio rerio. J Comp Physiol [A] 177:191-199

45. Mueller KL, Hoon MA, Erlenbach I, Chandrashekar J, Zuker CS, Ryba NJP (2005) The receptors and coding logic for bitter taste. Nature 434:225-229

46. Nikonov AA, Caprio J (2001) Electrophysiological evidence for a chemotopy of biologically relevant odors in the olfactory bulb of the channel catfish. J Neurophysiol 86:1869-1876

47. Nikonov A, Caprio J (2007) Highly specific olfactory receptor neurons for types of amino acids in the channel catfish. J Neurophysiol 97:1909-1918

48. Nikonov A, Caprio J (2007) Responses of olfactory forebrain units to amino acids in the channel catfish. J Neurophysiol 97:2490-2498

49. Ottoson D (1971) The electro-olfactogram. In: Beidler LM (ed) Handbook of sensory physiology, vol. 4, part 1. Springer, Berlin, pp 95-131

50. Reisert J, Matthews HR (1999) Adaptation of the odour-induced response in frog olfactory receptor cells. J Physiol 519:801-813

51. Revial MF, Sicard G, Duchamp A, Holley A (1982) New studies on odour discrimination in the frog's olfactory receptor cells. I. Experimental results. Chem Senses 7:175-190

52. Rolen SH, Caprio J (2007) Processing of bile salt odor information by single olfactory bulb neurons in the channel catfish. J Neurophysiol 97:4058-4068

53. Sato K, Suzuki N (2000) Contribution of $\mathrm{Ca}^{2+}$-activated $\mathrm{Cl}^{-}$ conductance to amino acid-induced inward current responses of ciliated olfactory neurons of the rainbow trout. J Exp Biol 203:253-262

54. Shoji T, Fujita K, Ban M, Hiroi O, Ueda H, Kurihara K (1994) Olfactory responses of chum salmon to amino acids are independent of large differences in salt concentrations between fresh and sea water. Chem Senses 19:609-615

55. Silver WL (1982) Electrophysiological responses from the peripheral olfactory system of the American eel, Anguilla rostrata. J Comp Physiol 148:379-388

56. Sorensen PW, Hara TJ, Stacey NE, Goetz FW (1988) Fprostaglandins function as potent olfactory stimulants that comprise the postovulatory female sex pheromone in goldfish. Biol Reprod 39:1039-1050

57. Sorensen PW, Caprio J (1998) Chemoreception. In: Evans DH (ed) The physiology of fishes. CRC, Boca Raton, pp 375-405

58. Speca DJ, Lin DM, Sorensen PW, Isacoff EY, Ngai J, Dittman AH (1999) Functional identification of a goldfish odorant receptor. Neuron 23:487-498

59. Trotier D, MacLeod P (1983) Intracellular recordings from salamander olfactory receptor cells. Brain Res 268:225-237

60. Valentincic TB, Caprio J (1994) Chemical and visual control of feeding and escape behaviors in the channel catfish Ictalurus punctatus. Physiol Behav 55:845-855

61. Valentincic T, Kralj J, Stenovec M, Koce A, Caprio J (2000) The behavioral detection of binary mixtures of amino acids and their individual components by catfish. J Exp Biol 203:3307-3317

62. Valentincic $T$ (2004) Taste in olfactory stimuli in behavior in fishes. In: Mogdans G, Von der Emde G, Kapoor BG (eds) The senses of fishes: adaptation of reception of natural stimuli. Narosa, New Delhi, pp 90-108

63. Valentincic T, Miklavc P, Dolensek J, Plibersek K (2005) Correlations between olfactory discrimination, olfactory receptor neuron responses and chemotopy of amino acids in fishes. Chem Senses 30(suppl.1):i312-i314

64. Zhao H, Ivic L, Otaki JM, Hashimoto M, Mikoshiba K, Firestein S (1998) Functional expression of mammalian odorant receptor. Science 279:237-242 